OPEN ACCESS

Edited by:

Steve Suib,

University of Connecticut,

United States

Reviewed by:

Huibiao Liu,

Institute of Chemistry (CAS), China

Gang Han,

University of Massachusetts Medical

School, United States

${ }^{*}$ Correspondence:

Guanying Chen

chenguanying@hit.edu.cn

Specialty section:

This article was submitted to Green and Sustainable Chemistry,

a section of the journal

Frontiers in Chemistry

Received: 25 November 2018 Accepted: 04 March 2019 Published: 27 March 2019

Citation:

Wang X and Chen G (2019) A Strategy for Prompt Phase Transfer of Upconverting Nanoparticles Through

Surface Oleate-Mediated

Supramolecular Assembly of Amino- $\beta$-Cyclodextrin

Front. Chem. 7:161.

doi: 10.3389/fchem.2019.00161

\section{A Strategy for Prompt Phase Transfer of Upconverting Nanoparticles Through Surface Oleate-Mediated Supramolecular Assembly of Amino- $\beta$-Cyclodextrin}

\author{
Xindong Wang and Guanying Chen* \\ MIIT Key Laboratory of Critical Materials Technology for New Energy Conversion and Storage, Key Laboratory of \\ Micro-systems and Micro-structures, School of Chemistry and Chemical Engineering, Harbin Institute of Technology, Ministry \\ of Education, Harbin, China
}

Lanthanide-doped upconverting nanoparticles (UCNPs) are promising for applications as wide as biosensing, bioimaging, controlled drug release, and cancer therapy. These applications require surface engineering of as-prepared nanocrystals, commonly coated with hydrophobic ligand of oleic acid, to enable an aqueous dispersion. However, literature-reported approaches often require a long time and/or multiple step treatment, along with several fold upconversion luminescence (UCL) intensity decrease. Here, we describe a strategy allowing oleate-capped UCNPs to become water-soluble and open-modified, with almost undiminished UCL, through ultrasonication of minutes. The prompt phase transfer was enabled by oleate-mediated supramolecular self-assembly of amino modified $\beta$-cyclodextrin (amino- $\beta$-CD) onto UCNPs surface. We showed that this method is valid for a wide range of UCNPs with quite different sizes (6-400 nm), various dopant types (Er, Tm, and Ho), and hierarchical structures (core, core-shell). Importantly, the amino group of amino- $\beta$-CD on the surface of treated UCNPs provide possibilities to introduce entities for biotargeting or functionalization, as exemplified here, a carboxylic-containing near infrared dye (Cy 7.5) that sensitizes UCNPs to enhance their UCL by $\sim 4,820$ fold when excited at $\sim 808 \mathrm{~nm}$. The described method has implications for all types of oleate-capped inorganic nanocrystals, facilitating their myriad bioapplications.

Keywords: lanthanides, upconverting, phase transfer, amino- $\beta$-cyclodextrin, supramolecular self-assembly

\section{INTRODUCTION}

Lanthanide-doped upconverting nanoparticles (UCNPs) are a new type of luminescent materials, which can produce visible or ultraviolet luminescence upon near infrared (NIR) excitation. They possess superior advantages over commonly seen luminescent materials (i.e., organic dyes, fluorescent proteins, and quantum dots), such as large anti-stoke shift, low imaging background, good colloidal stability, and deep tissue light activation (Chen et al., 2015; Wang et al., 2017). These merits empower them for uses in a comprehensive range of photonic and biophotonic applications, including solar cells, security encoding, and in particular, bio-imaging, biosensing, and light-activated cancer therapy. Most of these applications demand nanocrystal surface with critical 
engineered constituents, such as functional small molecule dyes, polymers, peptides, proteins, and nucleic acids, which, however, is generally unavailable from as-prepared UCNPs surface (Liu et al., 2011b; Wang et al., 2011; Chen et al., 2014, 2016).

The pristine ligands on the as-prepared UCNPs surface constitute the basic structure for surface engineering, which have an anchoring head group to coordinate to surface exposed metallic ions and an end group that points outside when dispersed. These ligands play a significant role in controlling the process of nanocrystal growth in solution as well as nanocrystal colloidal dispensability in solvents. Until now, commonly seen UCNPs with controlled and uniform sizes, shapes, crystal phases, are often synthesized with a high boiling point ligand of oleic acid (OA) (and sometimes together with oleylamine). The head group of $\mathrm{OA}$ is a carboxylic group, while the end group is a long alky chain, rendering them dispersible in non-polar organic solvents such as hexane. However, the hydrophobicity of the long alky chain prevents UCNPs for uses in aqueous media as well as for introduction of groups for biotargeting and functionalization. To solve this problem, a number of approaches have been developed and reported, such as ligand exchange (Wu et al., 2009; Shao et al., 2016; Wei et al., 2016; Lee et al., 2017), silica coating (Liu et al., 2013; Li et al., 2014b; Gnanasammandhan et al., 2016), oxidation of the $\mathrm{C}=\mathrm{C}$ bond in the OA ligand (Chen et al., 2008; Zhou et al., 2009; Dai et al., 2012), assembly of amphiphilic polymers (Camli et al., 2010; Danhier et al., 2012; Zou et al., 2016), and other available methods (Salinas et al., 2015; Liu et al., 2017). However, most of these literature-reported methods typically either require a long time and multiple step treatment to render UCNPs water-soluble, or the obtained aqueous nanocrystals often lack open-modified groups, such as - $\mathrm{NH}_{2}$ and $-\mathrm{COOH}$, for grafting needed functionalities (Li et al., 2014a, 2018). Moreover, these reported phase transfer processes are often in company with several fold UCL intensity decrease in UCNPs. It is still of importance to develop a simple and rapid approach to make OA-capped UCNPs hydrophilic and be open-modified for further functionalization.

Since the 1987 Nobel Prize in supramolecular chemistry, supramolecular recognition and self-assembly have been paid increased attentions in both scientific and technological developments (Yang et al., 2014; Mattia and Otto, 2015; Lehn, 2017). Cyclodextrin (CD), a water-soluble cyclic supramolecule, has a rigid well-defined ring structure and is able to firmly bind to some particular low-molecular-weight compounds, endowing these compounds new physiochemical properties (Harada, 2001; Descalzo et al., 2006). Indeed, recent results show that $\mathrm{CD}$ and its derivatives are able to form supramolecular complexes with OA molecules, providing possibilities for nanocrystal surface treatment to control their dispersibility properties (Wang et al., 2003; Liu et al., 2011a; Omer et al., 2011). Compared with commonly used surface treatment methods, the method of CD modification is simple and prompt (only needs ultrasonication for several minutes), leaving the pristine ligands anchored on UCNPs surface intact. As a result, this surface treatment method could avoid the formation of surface defects for energy trapping that typically leads to the decrease of UCL quantum yield.
In this work, we synthesized amino modified $\beta$-cyclodextrin (amino- $\beta-C D$ ) and then applied it to OA-capped UCNPs of varying type (different sizes, various types of lanthanide dopants, and core-shell structure), enabling them water-soluble and openmodified for functionalization. The interaction between the host molecule of amino- $\beta-C D$ and the guest surface molecule of OA allowed a prompt, stable, and straightforward self-assembly of amino- $\beta-C D$ onto the surface of UCNPs through ultrasonication of 2-4 min. Experimental results showed that the morphology, crystallographic phase, and UCL intensity of UCNPs are retained to a maximum. Importantly, the amino groups contained in the surface $\mathrm{CD}$ molecules allow to introduce a carboxylic-containing dye (Cy 7.5) onto the nanocrystal surface that can sensitize the nanocrystal to enhance its UCL by $\sim 4,820$ fold when excited at $\sim 808 \mathrm{~nm}$.

\section{MATERIALS AND METHODS}

\section{Reagents And Apparatus}

Oleic acid (OA) and 1-octadecene (ODE) were purchased from Sigma Aldrich (USA). Rare earth chloride hexahydrate $\left(\mathrm{YCl}_{3} \cdot 6 \mathrm{H}_{2} \mathrm{O} 99.9 \%, \mathrm{YbCl}_{3} \cdot 6 \mathrm{H}_{2} \mathrm{O} 99.9 \%, \mathrm{ErCl}_{3} \cdot 6 \mathrm{H}_{2} \mathrm{O}\right.$ 99.9\%, $\mathrm{TmCl}_{3} \cdot 6 \mathrm{H}_{2} \mathrm{O} 99.9 \%$, and $\mathrm{HoCl}_{3} \cdot 6 \mathrm{H}_{2} \mathrm{O} 99.9 \%$ ), rare earth

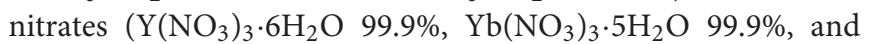
$\left.\mathrm{Er}\left(\mathrm{NO}_{3}\right)_{3} \cdot 5 \mathrm{H}_{2} \mathrm{O} 99.9 \%\right)$, sodium oleate, ammonium hydroxide, $\beta$-CD, epoxy chloropropane, neutral alumina (100-200 mesh), and sodium fluoride $(\mathrm{NaF})$ were from Aladdin (Shanghai, China). Hexane, methanol, ethanol, sodium hydroxide $(\mathrm{NaOH})$, and ammonium fluoride $\left(\mathrm{NH}_{4} \mathrm{~F}\right)$ were purchased from Xilong Scientific Co., Ltd (Guangdong, China). Yttrium oleate was prepared according to a method in a literature (Park et al., 2004). All the reagents were used without further purification.

The transmission electron microscope (TEM) images were acquired with a 100 CX II TEM microscope (JEM, Japan). Fourier transform infrared (FTIR) spectra were recorded on a Nicolet AVATAR360 FTIR spectrometer (Thermo Nicolet Corporation, USA). Luminescence spectra were obtained at a FLAME-TVIS-NIR Spectrometer Assembly (Ocean Optics, USA) with an excitation from a $\sim 980$ or $808 \mathrm{~nm}$ diode laser (CNI, Changchun). The integration time for the spectrometer was set to $600 \mathrm{~ms}$, while the power of 980 and $808 \mathrm{~nm}$ laser was set to 400 and $300 \mathrm{~mW}$, respectively, for all pertinent optical experiments. ${ }^{1} \mathrm{H}$ nuclear magnetic resonance (NMR) spectra were recorded on Bruker Avance 500 (500 MHz, USA). Luminescence lifetimes were recorded on the FLS 980 transient fluorescence spectrometer (Edinburgh Instruments, England).

\section{Preparation of $\mathrm{NaYF}_{4}: \mathrm{Yb}$, Er UCNPs Preparation of Small Size $(6 \mathrm{~nm}) \mathrm{NaYF}_{4}: 30 \% \mathrm{Yb}$, $2 \%$ Er UCNPs}

Small size $\mathrm{NaYF}_{4}: 30 \% \mathrm{Yb}, 2 \% \mathrm{Er}$ UCNPs $(6 \mathrm{~nm})$ were synthesized according to a previous procedure with modifications (Rinkel et al., 2016). Typically, $1.59 \mathrm{~g}$ of rare earth oleates ( $\mathrm{Y}, \mathrm{Yb}$ and Er oleates with a molar ratio of 0.68: 0.3: 0.02) and $4.06 \mathrm{~g}$ of sodium oleate were firstly combined with $20 \mathrm{~mL}$ OA and $20 \mathrm{~mL}$ octadecene in a $100 \mathrm{~mL}$ three neck flask. The mixture was degassed for $1 \mathrm{~h}$ at $100^{\circ} \mathrm{C}$ under $\mathrm{Ar}$ atmosphere and vigorous 
stirring. Then, $0.68 \mathrm{~g}$ of $\mathrm{NH}_{4} \mathrm{~F}$ was added to the solution, which maintained at $100^{\circ} \mathrm{C}$ for $30 \mathrm{~min}$ with $\mathrm{Ar}$ atmosphere protection. Subsequently, the reaction mixture containing sodium oleate, rare-earth oleates and $\mathrm{NH}_{4} \mathrm{~F}$ in a molar ratio of 8:1:11 was heated to $300^{\circ} \mathrm{C}$ with a heating rate of $16^{\circ} \mathrm{C} / \mathrm{min}$, and then kept at this temperature for $30 \mathrm{~min}$. After cooling to room temperature, excess ethanol was added to the solution to precipitate the nanocrystals, followed by centrifugation at $10,000 \mathrm{rpm} / \mathrm{min}$ for $5 \mathrm{~min}$. The collected precipitate was redispersed in a small amount of hexane, and then precipitated again with ethanol. Finally, the resultant UCNPs were collected with centrifugation and redispersed in $10 \mathrm{~mL}$ hexane.

\section{Preparation of Middle Size (42 nm) NaYF $4: 30 \% \mathrm{Yb}$, 2\%Er UCNPs}

Middle size $\mathrm{NaYF}_{4}$ : $30 \% \mathrm{Yb}, 2 \% \mathrm{Er}$ particles $(42 \mathrm{~nm})$ were synthesized as follows: $0.2063 \mathrm{~g} \quad \mathrm{YCl}_{3} .6 \mathrm{H}_{2} \mathrm{O}, 0.1162 \mathrm{~g}$ $\mathrm{YbCl}_{3} .6 \mathrm{H}_{2} \mathrm{O}$, and $0.0076 \mathrm{~g} \mathrm{ErCl}_{3} .6 \mathrm{H}_{2} \mathrm{O}(\mathrm{Y}, \mathrm{Yb}$ and $\mathrm{Er}$ chlorides in a molar ratio of $0.68: 0.3: 0.02$ ) were mixed with $9 \mathrm{~mL} \mathrm{OA}$ and $15 \mathrm{~mL}$ octadecene in a $100 \mathrm{~mL}$ three neck flask. The slurry mixture was heated to $150^{\circ} \mathrm{C}$ and kept for $30 \mathrm{~min}$ to form a transparent solution under Ar flow protection. Then the mixture was cooled down to $50^{\circ} \mathrm{C}$, followed by addition of $10 \mathrm{~mL}$ methanol containing $0.1482 \mathrm{~g} \mathrm{NH}_{4} \mathrm{~F}$ and $0.1000 \mathrm{~g} \mathrm{NaOH}$, and then stirred for $30 \mathrm{~min}$. Subsequently, the mixture was heated to $80^{\circ} \mathrm{C}$ and kept at this temperature for $30 \mathrm{~min}$ in order to evaporate methanol. Then the mixture was heated to $300^{\circ} \mathrm{C}$ with a rate of $15^{\circ} \mathrm{C} / \mathrm{min}$ under Ar flow, and maintained at $300^{\circ} \mathrm{C}$ for $60 \mathrm{~min}$. After cooling to room temperature, excess ethanol was added to the solution to precipitate the nanocrystals, followed by centrifugation at $6,000 \mathrm{rpm} / \mathrm{min}$ for $5 \mathrm{~min}$. The precipitate was collected and redispersed in a small amount of hexane, and then precipitated again with ethanol. Finally, the particles were separated by centrifugation and redispersed in $10 \mathrm{~mL}$ hexane.

\section{Preparation of Large Size $(400 \mathrm{~nm}) \mathrm{NaYF}_{4}: 30 \% \mathrm{Yb}$, $2 \%$ Er UCNPs}

Firstly, $1.0846 \mathrm{~g} \mathrm{NaOH}$ was mixed with $4 \mathrm{~mL} \mathrm{H}_{2} \mathrm{O}, 12 \mathrm{~mL} \mathrm{OA}$, and $6 \mathrm{~mL}$ ethanol, and stirred for $30 \mathrm{~min}$. Then, a certain amount of rare earth nitrates $(\mathrm{Y}, \mathrm{Yb}$, and Er nitrates in a molar ratio of 0.68: 0.3: 0.02) were added into the mixture and stirred for another $10 \mathrm{~min}$. Subsequently, $4 \mathrm{~mL} \mathrm{NaF}(1.25 \mathrm{M})$ solution was added and stirred for $30 \mathrm{~min}$. Finally, the solution was transferred to a stainless Teflon autoclave $(50 \mathrm{~mL})$, sealed, and heated at $180^{\circ} \mathrm{C}$ for $24 \mathrm{~h}$. After cooling to room temperature, excess ethanol was added to the solution to precipitate UCNPs, followed by centrifugation at $6,000 \mathrm{rpm} / \mathrm{min}$ for $5 \mathrm{~min}$. The precipitate was then redispersed in a small amount of hexane, and precipitated again with ethanol. Finally, the resultant particles were separated by centrifugation and redispersed in $10 \mathrm{~mL}$ hexane.

\section{Preparation of Middle Size $(42 \mathrm{~nm}) \mathrm{NaYF}_{4}: \mathrm{Yb}, \mathrm{X}(\mathrm{X}=$ $\mathrm{Er}, \mathrm{Tm}$, and Ho) UCNPs}

The synthesis procedures are similar with the one of middle size $\mathrm{NaYF}_{4}: \mathrm{Yb}$, Er particle. A total amount of $1 \mathrm{mmol}$ rare earth chloride hexahydrate $(\mathrm{Y}+\mathrm{Yb}+\mathrm{X}, \mathrm{X}=\mathrm{Er}, \mathrm{Tm}$, and $\mathrm{Ho})$ were mixed with $9 \mathrm{~mL} O A$ and $15 \mathrm{~mL}$ octadecene. The slurry mixture was heated to $150^{\circ} \mathrm{C}$ and kept for $30 \mathrm{~min}$ to form a transparent solution under Ar flow. Then the mixture was cooled down to $50^{\circ} \mathrm{C}$, followed by addition of $10 \mathrm{~mL}$ methanol containing $0.1482 \mathrm{~g} \mathrm{NH}_{4} \mathrm{~F}$ and $0.1000 \mathrm{~g} \mathrm{NaOH}$, and stirred for $30 \mathrm{~min}$. The mixture was then heated to $80^{\circ} \mathrm{C}$ and kept for $30 \mathrm{~min}$ in order to evaporate methanol. Subsequently, the solution was heated to $300^{\circ} \mathrm{C}$ with a rate of $15^{\circ} \mathrm{C} / \mathrm{min}$ under Ar flow, and maintained at $300^{\circ} \mathrm{C}$ for $60 \mathrm{~min}$. After naturally cooling to room temperature, excess ethanol was added to precipitate the nanocrystals followed by centrifugation at $6,000 \mathrm{rpm} / \mathrm{min}$ for $5 \mathrm{~min}$. The precipitate was then redispersed in a small amount of hexane and precipitated again with ethanol. Finally, the particles were separated by centrifugation and redispersed in $10 \mathrm{~mL}$ hexane.

\section{Preparation of Middle Size Core-Shell $(64 \mathrm{~nm}) \mathrm{NaYF}_{4}$ : $\mathrm{Yb}, \mathrm{Er} @ \mathrm{NaYF}_{4}$ UCNPs}

The middle size core particles $(42 \mathrm{~nm})$ of $\mathrm{NaYF}_{4}$ : $\mathrm{Yb}$, Er were synthesized using the above-mentioned procedure. The coating procedure of the inert shell layer of $\mathrm{NaYF}_{4}$ was described as follows. First, $0.5 \mathrm{mmol}$ of yttrium hexhydrate chloride was mixed with $9 \mathrm{~mL} \mathrm{OA}$ and $15 \mathrm{~mL}$ octadecene in a $100 \mathrm{~mL}$ three necked flask. The slurry mixture was then heated to $150^{\circ} \mathrm{C}$ and kept at this temperature for $30 \mathrm{~min}$ to form a transparent solution under Ar atmosphere protection. Subsequently, the mixture was cooled down to $50^{\circ} \mathrm{C}$, followed by addition of $10 \mathrm{~mL}$ methanol containing $0.0741 \mathrm{~g} \mathrm{NH}_{4} \mathrm{~F}$ and $0.0500 \mathrm{~g}$ $\mathrm{NaOH}$, and $10 \mathrm{~mL}$ hexane containing the $42 \mathrm{~nm}$ core $\mathrm{NaYF}_{4}: \mathrm{Yb}$, Er particles. After magnetic stirring at this temperature for $30 \mathrm{~min}$, the mixture was heated to $80^{\circ} \mathrm{C}$ and kept at this temperature for $30 \mathrm{~min}$ to evaporate methanol. The mixture was then heated to $300^{\circ} \mathrm{C}$ with a rate of $15^{\circ} \mathrm{C} / \mathrm{min}$ under $\mathrm{Ar}$ atmosphere protection, and maintained at this temperature for $60 \mathrm{~min}$. After cooling to room temperature, excess ethanol was added to precipitate the nanocrystals from the mixture, followed by centrifugation at $6,000 \mathrm{rpm} / \mathrm{min}$ for $5 \mathrm{~min}$. The precipitate was redispersed in a small amount of hexane and then precipitated with addition of excessive ethanol. Finally, the particles were collected by centrifugation and redispersed in 10 mL hexane.

\section{Preparation Of Amino- $\beta-C D$}

As shown in Figure 1a, the epoxy chloropropane was used to crosslink the amino group and the $\beta-\mathrm{CD}$ in a dilute alkali solution. The procedure to prepare amino modified $\beta-\mathrm{CD}$ is described as follows. Firstly, $8.1 \mathrm{~g} \beta$-CD and $6.7 \mathrm{~g} \mathrm{KOH}$ were added into $70 \mathrm{~mL} \mathrm{H}_{2} \mathrm{O}$, which was kept stirring until $\beta$-CD was completely dissolved. The resultant mixture was then heated to $50^{\circ} \mathrm{C}$, to which $3.4 \mathrm{~g}$ ammonium hydroxide and $10.2 \mathrm{~g}$ epoxy chloropropane were added in order. Subsequently, the mixture solution was heated to $60^{\circ} \mathrm{C}$ and maintained at this temperature for $1 \mathrm{~h}$. When completing the reaction, the $\mathrm{pH}$ of the solution was first adjusted to 5-6, and then $150 \mathrm{~mL}$ ethanol was poured into the solution at room temperature. The final product was purified via neutral alumina column, using an eluent of $60 \%$ ethanol. The resultant mixture was concentrated to $30 \mathrm{~mL}$ by evaporating redundant ethanol, followed by adding a large amount of absolute 

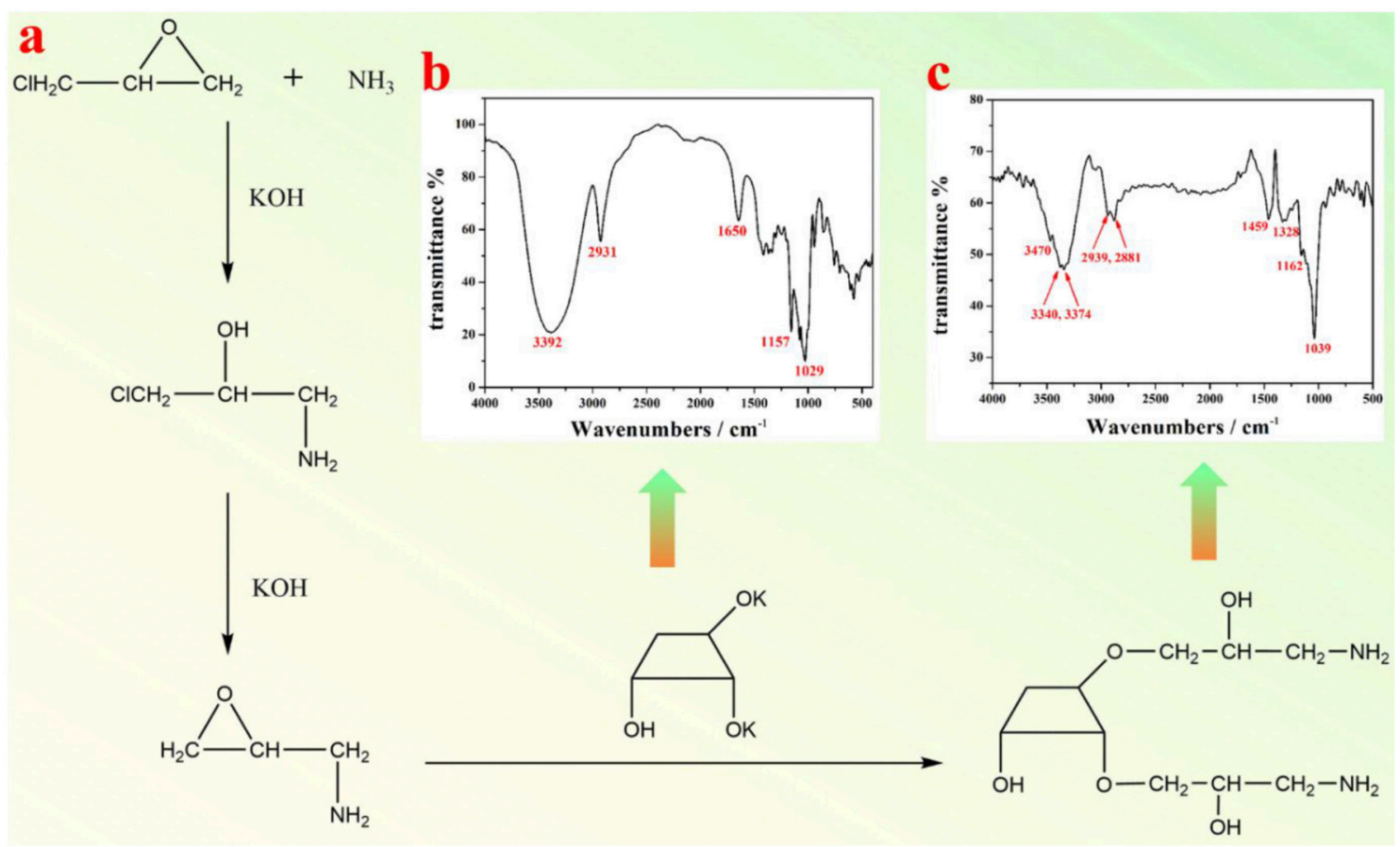

FIGURE 1 | (a) A schematic illustration of synthesis of amino- $\beta-C D$; FTIR spectra of (b) $\beta-C D$, and (c) amino- $\beta$-CD.

methanol and placed overnight. Finally, the amino- $\beta$-CD product was filtrated and dried in vacuum.

FTIR spectra of pristine $\beta$-CD (Figure 1b) and amino functionalized $\beta$-CD (Figure 1c) were both measured. As shown in Figure 1b, the bands at 2,931 $\mathrm{cm}^{-1}$ and $1,334-1,440 \mathrm{~cm}^{-1}$ represent the stretching and bending vibration of alkane $(\mathrm{C}-\mathrm{H})$. The bands at 3,392 and $1,650 \mathrm{~cm}^{-1}$ represent the stretching and bending vibration of $\mathrm{O}-\mathrm{H}$, and the bands at 1,029 and 1,157 $\mathrm{cm}^{-1}$ are both from the stretching vibration of $\mathrm{C}-\mathrm{O}$. After amino group modification, the vibration bands of $\mathrm{O}-\mathrm{H}$ and $\mathrm{C}-\mathrm{H}$ are both changed (move or split, Figure 1c), which are possibly due to the influence of linked amino alkane. Furthermore, the bending vibrations of $\mathrm{O}-\mathrm{H}$ at $1,650 \mathrm{~cm}^{-1}$ and the stretching vibration of $\mathrm{C}-\mathrm{O}$ at $1,157 \mathrm{~cm}^{-1}$ almost disappear, since the $\mathrm{OH}$ group has been replaced by the amino alkane group. The appearance of the stretching vibration of the $\mathrm{N}-\mathrm{H}$ group at 3,470 $\mathrm{cm}^{-1}$ clearly indicates the presence of amino group, and thus the successful preparation of amino- $\beta-C D$. The NMR spectrum of amino functionalized $\beta$-CD was shown in Figure S1. ${ }^{1} \mathrm{H}$ NMR of amino- $\beta$-CD $\left(500 \mathrm{MHz}, \mathrm{DMSO}-d_{6}\right) \delta 8.84(\mathrm{~s}, 4 \mathrm{H}), 7.49(\mathrm{~s}, 1 \mathrm{H})$, $7.39(\mathrm{~s}, 1 \mathrm{H}), 7.28(\mathrm{~s}, 1 \mathrm{H}), 5.78-5.71(\mathrm{~m}, 4 \mathrm{H}), 5.59(\mathrm{~s}, 2 \mathrm{H}), 5.03(\mathrm{~s}$, $6 \mathrm{H}), 4.84(\mathrm{~s}, 3 \mathrm{H}), 4.58(\mathrm{~s}, 6 \mathrm{H}), 4.03(\mathrm{~s}, 2 \mathrm{H}), 3.99-3.94(\mathrm{~m}, 1 \mathrm{H})$, $3.87(\mathrm{~s}, 2 \mathrm{H}), 3.69(\mathrm{~s}, 15 \mathrm{H}), 3.63(\mathrm{~s}, 12 \mathrm{H}), 3.56(\mathrm{~s}, 3 \mathrm{H}), 3.36(\mathrm{ddt}, J$ $=31.8,15.0,6.9 \mathrm{~Hz}, 14 \mathrm{H}), 3.23-3.16(\mathrm{~m}, 21 \mathrm{H}), 3.00(\mathrm{~s}, 1 \mathrm{H}), 2.87$ (s, 2H).

\section{Surface Modification of OA-Capped UCNPs With Amino- $\beta$-CD}

Surface treatment of OA-capped UCNPs was realized through an OA-targeting supermolecular self-assembly of amino- $\beta$-CD on to the nanoparticle surface (consult Figure 2a). In a typical procedure, a certain amount $(1 \mathrm{~mL})$ of as-prepared UCNPs in hexane (concentration of $10 \mathrm{mg} / \mathrm{mL}$ ) were dispersed in $10 \mathrm{~mL}$ water solution containing amino- $\beta-\mathrm{CD}(10 \mathrm{mg} / \mathrm{mL})$ and $0.06 \mathrm{M}$ hydrochloric acid. The mixture was ultrasonically treated for 2$4 \mathrm{~min}$ at room temperature. Note that, longer ultrasound time is needed for smaller sized particles $(6 \mathrm{~nm})$. Finally, the resultant mixture was centrifugally separated to collect the product, which was then washed three more times with $10 \mathrm{~mL}$ deionized water, and finally stored in $5 \mathrm{~mL}$ deionized water.

\section{Attachment of Cy 7.5 to Amino- $\beta-C D$ Modified NaYF 4 : Yb, Er UCNPs}

The attachment of near infrared Cy 7.5 dye to the surface of amino $\beta$-CD modified $\mathrm{NaYF}_{4}$ : $\mathrm{Yb}$, Er UCNPs was realized through direct formation of a covalent amide bond between the carboxyl group of Cy 7.5 dye and the amino moiety of amino $\beta-\mathrm{CD}$, with presence of cross-linking reagents (EDC/NHS) (consult Figure 5A). Specifically, $100 \mu \mathrm{L}$ of Cy 7.5 dye water solution $(2 \mathrm{mg} / \mathrm{mL})$ was added into $1 \mathrm{~mL}$ water solution containing EDC $(400 \mathrm{mM})$ and NHS $(100 \mathrm{mM})$, which was freshly prepared before the use for activation of the carboxyl group for $2 \mathrm{~h}$. Then, $2 \mathrm{~mL}$ of amino- $\beta$-CD modified UCNPs $(10 \mathrm{mg} / \mathrm{mL})$ water solution were added to the activated Cy 7.5 solution, and stirred for $4 \mathrm{~h}$ at room temperature. Finally, the resultant mixture was centrifugally separated to collect the product, followed by washing three times with $10 \mathrm{~mL}$ dimethyl formamide (DMF), and then stored in $5 \mathrm{~mL}$ DMF for measurements. 


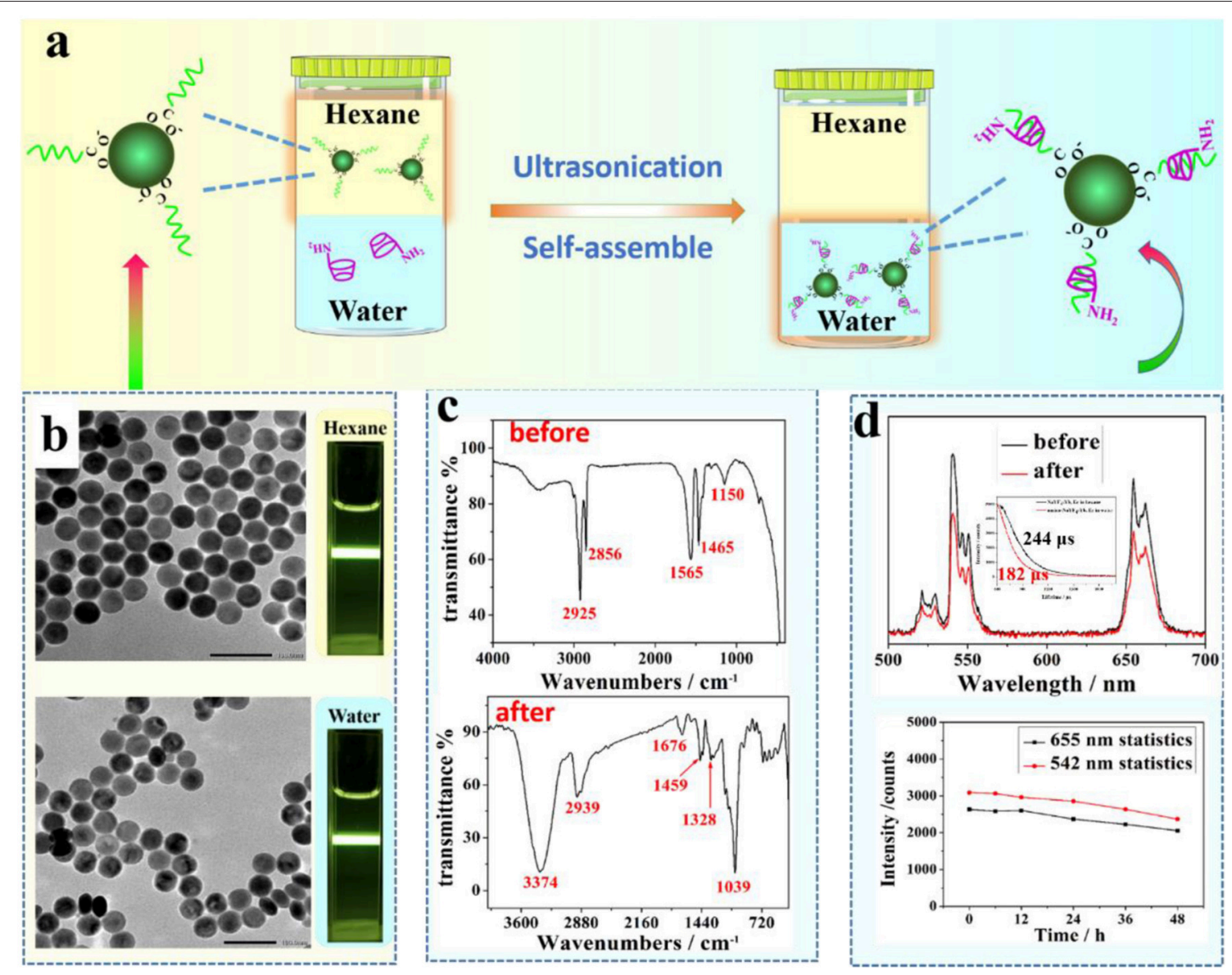

FIGURE 2 | (a) A schematic illustration of the phase transfer process of UCNPs from hexane to water; (b) TEM images of NaYF 4 :Yb, Er UCNPs before (upper figure) and after (bottom figure) surface treatment, (c) FTIR spectra of UCNPs before (upper figure) and after (bottom figure) surface treatment with amino- $\beta$-CD; (d) A comparison of UCL spectra of $\mathrm{NaYF}_{4}: \mathrm{Yb}$, Er UCNPs before and after surface treatment (upper figure); The inert is the relevant lifetime changes. an evaluation of water stability of amino- $\beta$-CD modified UCNPs through monitoring UCL peak change at 655 and $542 \mathrm{~nm}$ over a period of time (bottom figure).
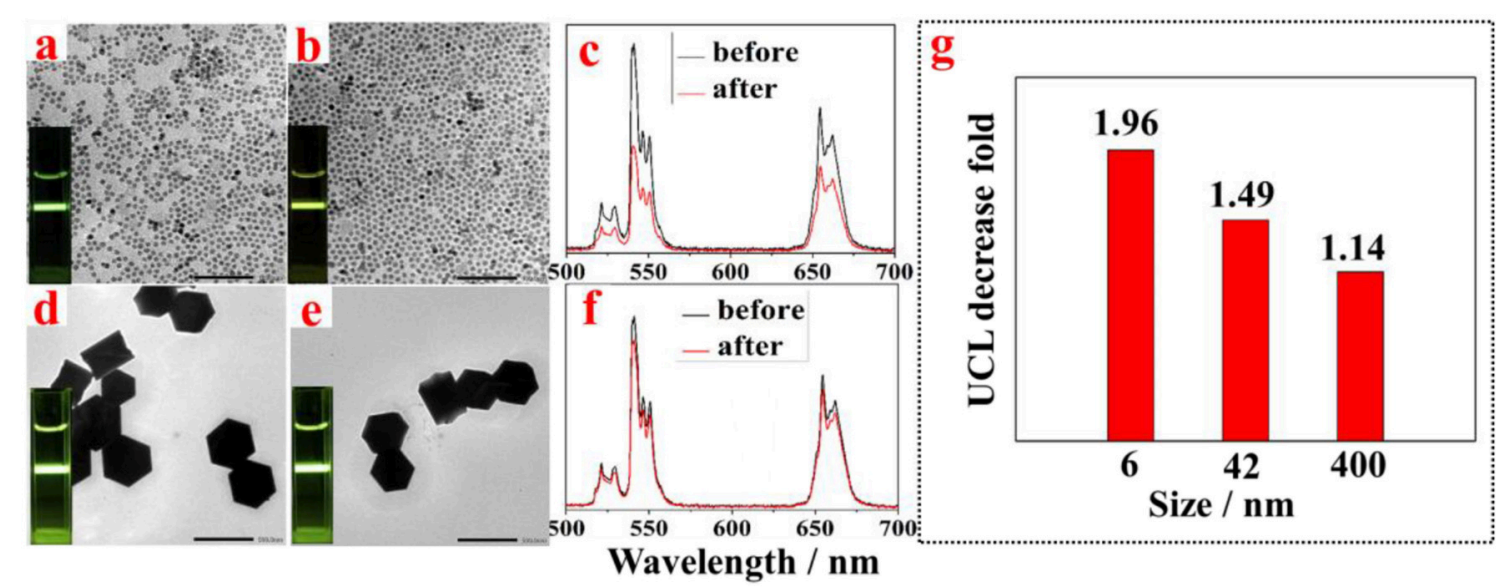

FIGURE 3 | TEM images of NaYF 4 :Yb, Er UCNPs with small size before (a) and after (b) surface treatment, and with large size before (d) and after (e) surface treatment; the corresponding UCL spectra from NaYF 4 :Yb, Er UCNPs with (c) small size and (f) before and after surface treatment; (g) The observed UCL decrease fold vs. the size of $\mathrm{NaYF}_{4}: \mathrm{Yb}$, Er UCNPs after surface treatment with amino- $\beta-\mathrm{CD}$. 


\section{RESULTS AND DISCUSSION}

Figure 2 shows the result of surface treatment of middle size $\mathrm{NaYF}_{4}: \mathrm{Yb}$, Er UCNPs $(42 \mathrm{~nm}$ ) with amino- $\beta$-CD through ultrasonication of two min. An intercalation of the long alky chain of $\mathrm{OA}$ molecules with the rigid ring of $\beta-\mathrm{CD}$ allows a stable attachment of amino- $\beta$-CD molecules to the nanocrystal surface (Figure 2a). The hydrophilicity of amino$\beta$-CD, therefore, imparts a phase transfer of hydrophobic OAcapped UCNPs from organic phase (hexane) in the upper layer to aqueous phase at the bottom. A successful phase transfer can be indicated by an observation of strong UCL from surface-treated UCNPs in an aqueous dispersion (Figure 2b). To further demonstrate the successful phase transfer, we acquired FTIR spectra of UCNPs before and after amino- $\beta$ $\mathrm{CD}$ surface treatment (Figure 2c). Before surface treatment, the bands at $2,856 / 2,925 \mathrm{~cm}^{-1}$ and $1,465 \mathrm{~cm}^{-1}$ are from the stretching and bending vibration of alkane $(\mathrm{C}-\mathrm{H})$, while the bands at 1,150 and $1,565 \mathrm{~cm}^{-1}$ represent the stretching vibration of $\mathrm{C}-\mathrm{O}$ and $\mathrm{C}=\mathrm{O}$ groups, arising from the $\mathrm{OA}$ ligand molecule on the surface. After surface modification, the vibration bands of $\mathrm{OA}$ at both 1,150 and $1,565 \mathrm{~cm}^{-1}$ nearly disappear, being attributed to the host-guest intercalation of the amino- $\beta-\mathrm{CD}$ and the $\mathrm{OA}$ molecule. In addition, the characteristic vibration bands at $1,039,1,328,1,459$, 2,939 , and $3,374 \mathrm{~cm}^{-1}$ of amino- $\beta$-CD molecule (Figure 1), emerges after surface treatment, which indicates the successful attachment of amino- $\beta$-CD molecules onto the surface of OAcapped UCNPs.
The amino- $\beta$-CD surface treatment procedure does not produce overt effects on UCNPs size and morphology, as the $\mathrm{NaYF}_{4}: \mathrm{Yb}$, Er UCNPs, before and after treatment, are both shown to be spherical with a narrow size distribution of about $42 \mathrm{~nm}$ (Figure 2b). In addition, UCL spectra of the middle size UCNPs before (dispersed in hexane) and after (dispersed in water) amino- $\beta$-CD treatment were acquired and shown in Figure 2d. The UCL peaks at 525/542 and $655 \mathrm{~nm}$, located in the visible spectral region, correspond to the ${ }^{2} \mathrm{H}_{11 / 2} /{ }^{4} \mathrm{~S}_{3 / 2} \rightarrow$ ${ }^{4} \mathrm{I}_{15 / 2}$, and ${ }^{4} \mathrm{~F}_{9 / 2} \rightarrow{ }^{4} \mathrm{I}_{15 / 2}$ transitions of $\mathrm{Er}^{3+}$ ions, respectively, in good agreement with previously reported results (Chen et al., 2014). In addition, after phase transfer to water, the lifetime of $\mathrm{NaYF}_{4}: \mathrm{Yb}$, Er UCNPs slightly decreases from 244 to $182 \mu \mathrm{s}$, implying that the integrity of prestine surface was largely retained (Figure $\mathbf{2 d}$ ). The UCL intensity remain almost undiminished after the phase conversion from hexane to water, showing a slight decrease of 1.5 fold. This conclusion can also be suggested from a direct comparison of UCL photographic images in both hexane and water (Figure 2b). To investigate the stability of amino- $\beta$-CD modified UCNPs, room temperature UCL spectra of these surface-treated UCNPs were measured at different time points $(0,6,12,24,36$, and $48 \mathrm{~h})$ over a period of 2 days. As shown in the bottom of Figure 2d, the luminescence intensities of Er at 542 and $655 \mathrm{~nm}$ were merely slightly decreased with an increase of time, and retained about $90 \%$ of UCL intensity for up to 2 days, demonstrating the good stability of amino- $\beta$-CD surface-treated UCNPs. The amino-CD modified nanoparticles also showed good photostability using $400 \mathrm{~mW} 980 \mathrm{~nm}$ laser illuminated for $30 \mathrm{~min}$ (Figure S2),

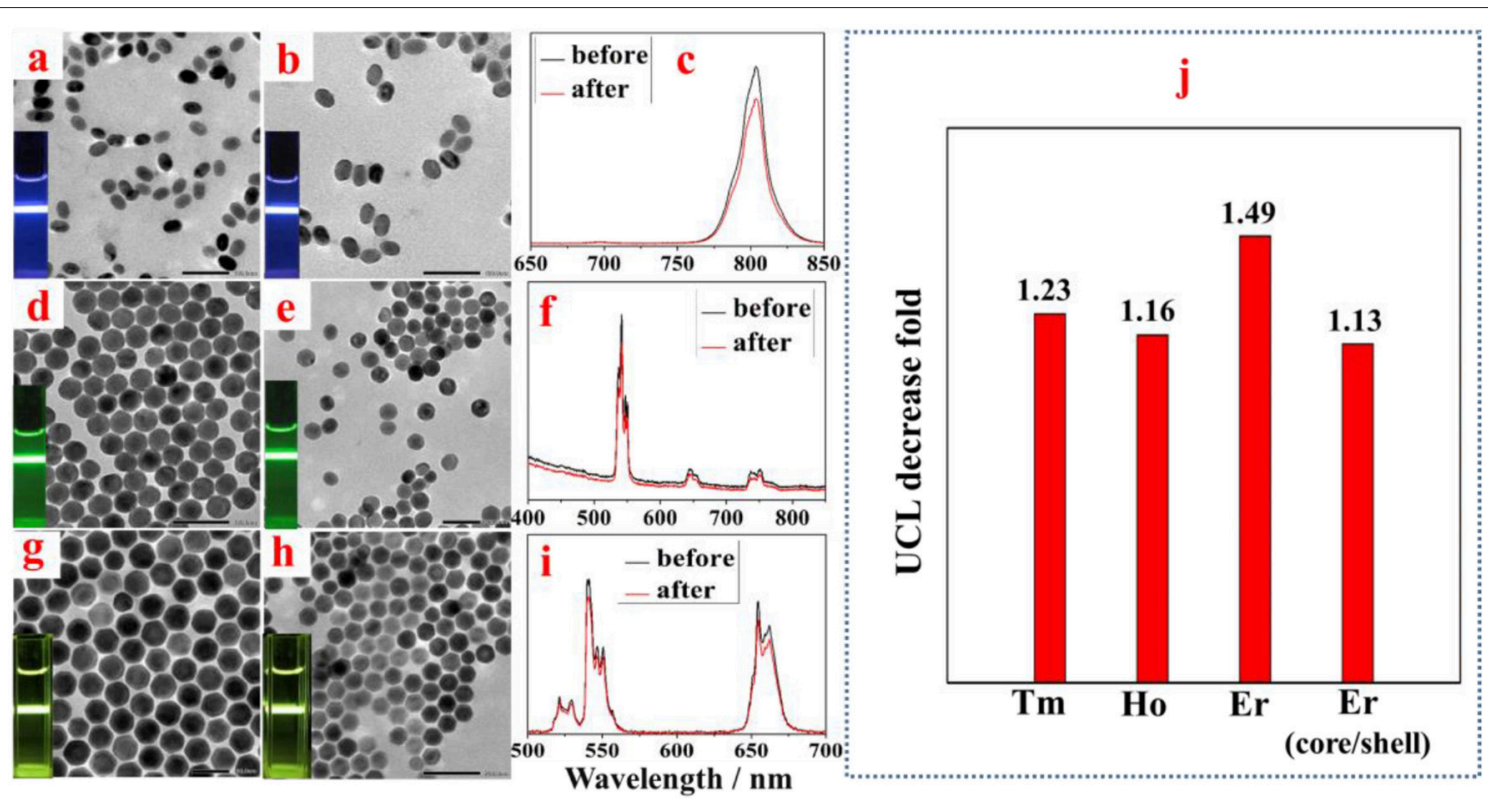

FIGURE 4 | TEM images of middle size NaYF 4 :Yb,Tm (a,b), NaYF 4 :Yb, Ho (d,e), and core-shell NaYF 4 :Yb, Er@NaYF 4 UCNPs (g,h) before and after surface treatment. The corresponding UCL spectra from NaYF $:$ Yb,Tm (c), NaYF 4 :Yb, Ho (f), and core-shell NaYF 4 :Yb, Er@NaYF 4 UCNPs (i), respectively. The column graph data in (j) depicts a comparison of surface treatment induced UCL decrease fold for UCNPs doped with different activators (Tm, Ho, and Er) or with core/shell structure. 
and great chemical stability when aged in water for $12 \mathrm{~h}$ (Figure S3).

To test whether the described approach can be valid for small and large OA-capped UCNPs, we synthesized UCNPs of small size $(6 \mathrm{~nm})$ and large size $(400 \mathrm{~nm})$ and implemented the phase transfer procedure. TEM images of the $\mathrm{NaYF}_{4}: \mathrm{Yb}, \mathrm{Er}$ UCNPs of small and large size UCNPs before and after amino- $\beta$ CD modification are correspondingly shown in Figures $\mathbf{3 a}, \mathbf{b}, \mathbf{d}, \mathbf{e}$, respectively. As expected, no overt changes of morphology and size were observed. UCNPs of both small and large sizes were successfully transferred into aqueous phase, displaying intense UCL in water (small size, the inset of Figure $\mathbf{3 b}$; large size, the inset of Figure 3e). The UCL intensity from UCNPs of both sizes (small size, Figure 3c; large size, Figure 3f) were almost retained. This can also be seen from a comparison of UCL photographic images before and after phase transfer (small size, the inset of Figure $\mathbf{3 a}$ vs. Figure $\mathbf{3} \mathbf{b}$; large size, the inset of Figure 3d vs. Figure 3e). Note that the fold of surface treatment induced UCL decrease diminishes with an increase of the size of UCNPs, from $\sim 2$ fold for $6 \mathrm{~nm}$ UCNPs to $\sim 1.1$ fold for $400 \mathrm{~nm}$ UCNPs (Figure 3g). This observation possibly stems from the decreased surface to volume ratio with an increase of particle size. It is known that the large surface to volume ratio can produce pronounced UCL quenching effect, as a large number of rare earth ions will be exposed to surrounding quenching centers (surface defects, high energy vibrations from ligands and solvents) (Chen et al., 2014). As a result, after phase transfer, smaller size UCNPs with larger surface to volume ratio are more prone to be quenched by water molecules from solvent, thus resulting in higher UCL decrease. However, it should be noted that the observed maximum UCL decrease is merely 2 fold for small size UCNPs $(6 \mathrm{~nm})$. This result indicates that the intercalation of amino- $\beta$-CD to the surface of OA-capped UCNPs is able to retain the integrity of pristine particles, without creating noticeable surface defects for substantial UCL quenching that were commonly seen in literature- reported phase transfer methods.

To investigate the effect of amino- $\beta$-CD treatment on the UCL of other types of UCNPs, we prepared a set of middle size $(42 \mathrm{~nm})$ UCNPs with different emission bands and with a core/shell structure (core $42 \mathrm{~nm}$, core-shell $64 \mathrm{~nm}$ ). As shown in Figure 4, TEM images of $\mathrm{NaYF}_{4}: \mathrm{Yb}, \mathrm{X}(\mathrm{X}=\mathrm{Tm}$, or Ho) UCNPs $(42 \mathrm{~nm})$ and $\mathrm{NaYF}_{4}: \mathrm{Yb}, \mathrm{Er} @ \mathrm{NaYF}_{4}$ core-shell UCNPs $(64 \mathrm{~nm})$ before and after amino- $\beta-C D$ modification present no identifiable changes on the morphologies and sizes, as expected. In addition, no spectral and relative intensities changes were observed for both $\mathrm{NaYF}_{4}: \mathrm{Yb}, \mathrm{X}$ (X = Tm, or Ho) UCNPs and $\mathrm{NaYF}_{4}: \mathrm{Yb}, \mathrm{Er} @ \mathrm{NaYF}_{4}$ core-shell UCNPs after surface modification with amino- $\beta$-CD. The UCL intensities show a slight decrease after the conversion from hexane to water, which can be ascribed to the quenching effect induced by energetic hydroxyl $(-\mathrm{OH})$ group of water molecules. However, it should be noted that the UCL quenching fold for middle size $(42 \mathrm{~nm})$ $\mathrm{NaYF}_{4}: \mathrm{Yb}, \mathrm{Tm}$ and $\mathrm{NaYF}_{4}: \mathrm{Yb}$, Ho are both about 1.2, a little smaller than the 1.5 fold for middle size $(42 \mathrm{~nm}) \mathrm{NaYF}_{4}: \mathrm{Yb}, \mathrm{Er}$, presenting negligible quenching effect (Figure 4j). Importantly, the UCL quenching fold for the $\mathrm{NaYF}_{4}: \mathrm{Yb}, \mathrm{Er} @ \mathrm{NaYF}_{4}$ core-shell
UCNPs is just 1.1 fold, displaying almost identical UCL intensity before and after amino- $\beta$-CD treatment. This indicates that the aqueous environment produces no quenching effect for UCL from the core/shell structure UCNPs, which can possibly be due to the spatial isolation of the core from the surrounding environment.

The amino group on the surface of lanthanide-doped nanocrystals provide numerous open-modified opportunities for further functionalizations through a covalent linkage of functional molecules, such as dye, protein, and ribonucleic acid. As a proof-of-concept experiment, a type of carboxyl group functionalized near infrared dye (Cy 7.5) was linked onto the surface of $\mathrm{NaYF}_{4}: \mathrm{Yb}$, Er UCNPs through formation of an amide bond with the amino group contained in amino- $\beta-C D$ on the nanocrystal surface (Figure 5a). It has been shown that organic dye sensitization is promising to solve the weak and narrow absorption problem of lanthanide-doped UCNPs, as the absorption of an organic dye is three orders of magnitude higher than that of a lanthanide ion. After light absorption, efficient nonradative energy transfer from organic dyes to the ytterbiurm (Yb) ions on the nanocrystal surface can empower an efficient photon upconversion through well-established $\mathrm{Yb}$ $\mathrm{X}(\mathrm{X}=\mathrm{Er}, \mathrm{Ho}, \mathrm{Tm})$ interactions, here $\mathrm{X}=\mathrm{Er}$ (Chen et al., 2015; Wang et al., 2017). The $\beta$-CD modified $\mathrm{NaYF}_{4}: \mathrm{Yb}, \mathrm{Er}$ UCNPs without Cy 7.5 dyes served as a control sample. As shown in Figure $\mathbf{5 b}$, under an excitation at $808 \mathrm{~nm}$, the $\mathrm{Cy}$ 7.5 linked- $\mathrm{NaYF}_{4}: \mathrm{Yb}$, Er UCNPs exhibit intense UCL with characteristic peaks of Er at 542 and $655 \mathrm{~nm}$, in marked contrast

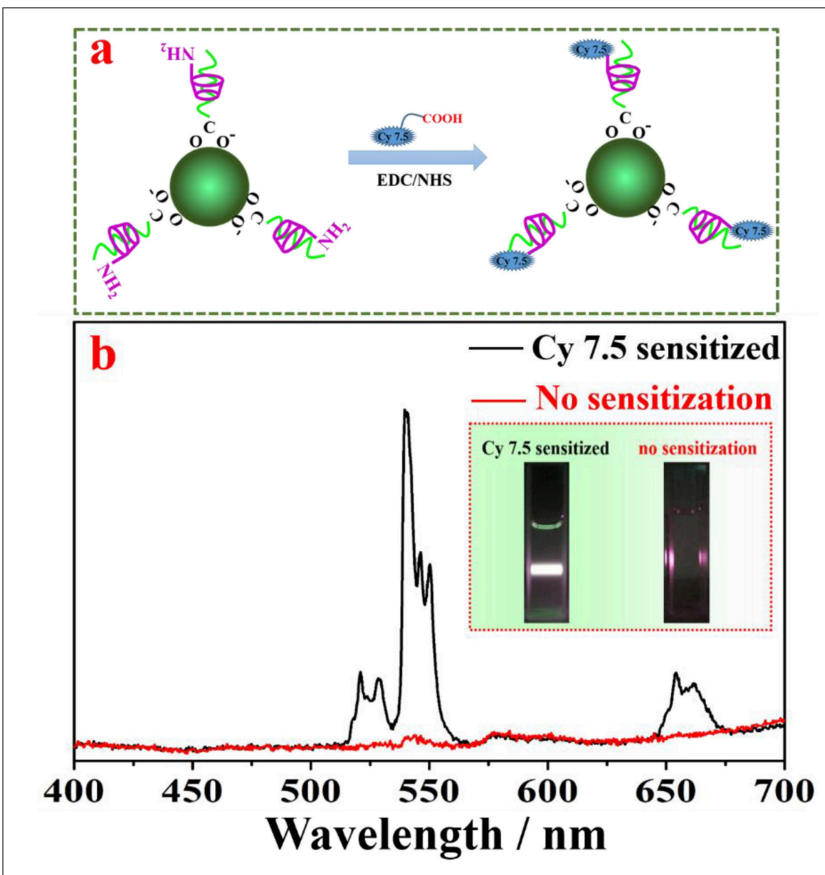

FIGURE 5 | (a) A schematic illustration of grafting Cy 7.5 dyes to the surface of UCNPs; (b) UCL spectra of NaYF 4 :Yb, Er UCNPs with and without Cy 7.5 dyes on the nanocrystal surface, showing UCL enhancement of $\sim 4,820$ fold due to the antenna effect of the grafted dye. 
to none UCL from the control sample. The sensitization effect can take place through either covalently linked dyes or noncovalently linked dyes. We estimated about $80 \%$ sensitization enhancement originates from the covalent linkage of $\mathrm{Cy} 7.5$ dyes (Figure S4). In addition, we calculated that the integrated UCL from Cy 7.5 dye-modified UCNPs in the spectral range of $400-700 \mathrm{~nm}$ was about $\sim 4,820$ fold higher than that of UCL from the control sample. This significant UCL enhancement can be clearly discerned from the photographic UCL images (the inset of Figure 5b), which unambiguously originated from the sensitization of the $\mathrm{NaYF}_{4}: \mathrm{Yb}$, Er UCNPs by the linked Cy 7.5 dye on the UCNPs surface.

\section{CONCLUSIONS}

In summary, we have developed a simple approach for prompt conversion of hydrophobic lanthanide-doped UCNPs, commonly capped with OA ligand, to be water-soluble and open-modified for functionalization, based on OA-targeting supramolecular self-assembly of amino- $\beta$-CD. This method was shown to be valid for UCNPs with a broad spectrum of sizes $(6-400 \mathrm{~nm})$, a set of rare earth dopants $(\mathrm{Yb} / \mathrm{Er}$, $\mathrm{Yb} / \mathrm{Ho}$, and $\mathrm{Yb} / \mathrm{Tm}$ ), as well as core-shell structure through ultrasonication of 2-4 min. Importantly, UCL intensities from surface treated UCNPs were almost identical to their parent OA-capped UCNPs. Moreover, these amino- $\beta-C D$ modified UCNPs were found to be stable over $48 \mathrm{~h}$ without overt diminishment of their UCL intensities. The amino group on the surface of resultant amino- $\beta$-CD modified UCNPs creates

\section{REFERENCES}

Camli, S. T., Buyukserin, F., Balci, O., and Budak, G. G. (2010). Size controlled synthesis of sub- $100 \mathrm{~nm}$ monodisperse poly(methylmethacrylate) nanoparticles using surfactant-free emulsion polymerization. J. Colloid Interface Sci. 344, 528-532. doi: 10.1016/j.jcis.2010.01.041

Chen, G., Damasco, J., Qiu, H., Shao, W., Ohulchanskyy, T. Y., Valiev, R. R., et al. (2015). Energy-cascaded upconversion in an organic dyesensitized core/shell fluoride nanocrystal. Nano Lett. 15, 7400-7407. doi: $10.1021 /$ acs.nanolett.5b02830

Chen, G., Qiu, H., Prasad, P. N., and Chen, X. (2014). Upconversion nanoparticles: design, nanochemistry, and applications in theranostics. Chem. Rev. 114, 5161-5214. doi: 10.1021/cr400425h

Chen, G., Roy, I., Yang, C., and Prasad, P. N. (2016). Nanochemistry and nanomedicine for nanoparticle-based diagnostics and therapy. Chem. Rev. 116, 2826-2885. doi: 10.1021/acs.chemrev.5b00148

Chen, Z., Chen, H., Hu, H., Yu, M., Li, F., Zhang, Q., et al. (2008). Versatile synthesis strategy for carboxylic acid-functionalized upconverting nanophosphors as biological Labels. J. Am. Chem. Soc. 130, 3023-3029. doi: $10.1021 / \mathrm{ja} 076151 \mathrm{k}$

Dai, Y., Yang, D., Ma, P. A., Kang, X., Zhang, X., Li, C., et al. (2012). Doxorubicin conjugated NaYF4: $\mathrm{Yb}^{3+} / \mathrm{Tm}^{3+}$ nanoparticles for therapy and sensing of drug delivery by luminescence resonance energy transfer. Biomaterials 33, 8704-8713. doi: 10.1016/j.biomaterials.2012.08.029

Danhier, F., Ansorena, E., Silva, J. M., Coco, R., Le Breton, A., and Préat, V. (2012). PLGA-based nanoparticles: an overview of biomedical applications. J. Control. Release 161, 505-522. doi: 10.1016/j.jconrel.2012.01.043

Descalzo, A. B., Martínez-Máñez, R., Sancenón, F., Hoffmann, K., and Rurack, K. (2006). The supramolecular chemistry of organic-inorganic hybrid materials. Angew. Chem. Int. Ed. 45, 5924-5948. doi: 10.1002/anie.200600734 opportunities to graft other functionalities, as exemplified here, by a covalent linkage of the carboxylic-containing dye (Cy 7.5) to the surface, which sensitizes $42 \mathrm{~nm} \mathrm{NaYF}_{4}: \mathrm{Yb} / \mathrm{Er}$ UCNPs, enhancing their UCL by $\sim 4,820$ fold (when excited at $808 \mathrm{~nm}$ ). The described approach here holds great promise for surface treatment of other kinds of OA or OA-analogs capped inorganic nanocrystals, fostering their applications in nanomedicine and theranostics.

\section{AUTHOR CONTRIBUTIONS}

$\mathrm{XW}$ and GC conceived the idea and designed the investigation. XW contributed to the synthesis and characterization of the materials. XW and GC analyzed the data and wrote the manuscript. All authors approved the submitted version.

\section{ACKNOWLEDGMENTS}

This work was supported in part by the grants from the National Natural Science Foundation of China (51672061), and the Fundamental Research Funds for the Central Universities, China (HIT. BRETIV.201503).

\section{SUPPLEMENTARY MATERIAL}

The Supplementary Material for this article can be found online at: https://www.frontiersin.org/articles/10.3389/fchem. 2019.00161/full\#supplementary-material
Gnanasammandhan, M. K., Idris, N. M., Bansal, A., Huang, K., and Zhang, Y. (2016). Near-IR photoactivation using mesoporous silica-coated NaY[F.sub.4]:Yb,Er/Tm upconversion nanoparticles. Nat. Protoc. 11, 688-713. doi: 10.1038/nprot.2016.035

Harada, A. (2001). Cyclodextrin-based molecular machines. Acc. Chem. Res. 34, 456-464. doi: 10.1021/ar0001741

Lee, J., Yoo, B., Lee, H., Cha, G. D., Lee, H.-S., Cho, Y., et al. (2017). Ultra-wideband multi-dye-sensitized upconverting nanoparticles for information security application. Adv. Mater. 29:1603169-n/a. doi: 10.1002/adma.201603169

Lehn, J.-M. (2017). Supramolecular chemistry: where from? Where to? Chem. Soc. Rev. 46, 2378-2379. doi: 10.1039/C7CS00115K

Li, J., Jiu, T., Tao, G. H., Wang, G., Sun, C., Li, P., et al. (2014a) Manipulating surface ligands of Copper Sulfide nanocrystals: synthesis, characterization, and application to organic solar cells. J. Colloid Interface Sci. 419, 142-147. doi: 10.1016/j.jcis.2013.12.057

Li, J., Kuang, C., Zhao, M., Zhao, C., Liu, L., Lu, F., et al. (2018). Ternary CuZnS nanocrystals: synthesis, characterization, and interfacial application in perovskite solar cells. Inorg. Chem. 57, 8375-8381. doi: 10.1021/acs.inorgchem.8b01030

Li, X., Zhou, L., Wei, Y., El-Toni, A. M., Zhang, F., and Zhao, D. (2014b). Anisotropic growth-induced synthesis of dual-compartment janus mesoporous silica nanoparticles for bimodal triggered drugs delivery. J. Am. Chem. Soc. 136, 15086-15092. doi: 10.1021/ja508733r

Liu, B., Deng, X., Xie, Z., Cheng, Z., Yang, P., and Lin, J. (2017). Thiol-ene click reaction as a facile and general approach for surface functionalization of colloidal nanocrystals. Adv. Mater. 29:1604878-n/a. doi: 10.1002/adma.201604878

Liu, J., Bu, W., Pan, L., and Shi, J. (2013). NIR-triggered anticancer drug delivery by upconverting nanoparticles with integrated azobenzene-modified mesoporous silica. Angew. Chem. Int. Ed. 52, 4375-4379. doi: 10.1002/anie.201300183 
Liu, Q., Chen, M., Sun, Y., Chen, G., Yang, T., Gao, Y., et al. (2011a). Multifunctional rare-earth self-assembled nanosystem for tri-modal upconversion luminescence/fluorescence/positron emission tomography imaging. Biomaterials 32, 8243-8253. doi: 10.1016/j.biomaterials.2011.07.053

Liu, Q., Sun, Y., Yang, T., Feng, W., Li, C., and Li, F. (2011b). Sub-10 nm hexagonal lanthanide-doped NaLuF4 upconversion nanocrystals for sensitive bioimaging in vivo. J. Am. Chem. Soc. 133, 17122-17125. doi: 10.1021/ja207078s

Mattia, E., and Otto, S. (2015). Supramolecular systems chemistry. Nat. Nano. 10, 111-119. doi: 10.1038/nnano.2014.337

Omer, M., Haider, S., and Park, S.-Y. (2011). A novel route for the preparation of thermally sensitive core-shell magnetic nanoparticles. Polymer 52, 91-97. doi: 10.1016/j.polymer.2010.11.011

Park, J., An, K., Hwang, Y., Park, J.-G., Noh, H.-J., Kim, J.-Y., et al. (2004). Ultralarge-scale syntheses of monodisperse nanocrystals. Nat. Mater. 3, 891-895. doi: 10.1038/nmat 1251

Rinkel, T., Raj, A. N., Dühnen, S., and Haase, M. (2016). Synthesis of $10 \mathrm{~nm} \beta . \mathrm{SyF}_{4}: \mathrm{Yb}, \mathrm{Er} / \mathrm{NaYF}_{4}$ core/shell upconversion nanocrystals with $5 \mathrm{~nm}$ particle cores. Angew. Chem. Int. Ed. Engl. 55, 1164-1167. doi: 10.1002/anie. 201508838

Salinas, B., Ruiz-Cabello, J., Lechuga-Vieco, A. V., Benito, M., and Herranz, F. (2015). Surface-functionalized nanoparticles by olefin metathesis: a chemoselective approach for in vivo characterization of atherosclerosis plaque. Chem. A Eur. J. 21, 10450-10456. doi: 10.1002/chem.201500458

Shao, W., Chen, G., Kuzmin, A., Kutscher, H. L., Pliss, A., Ohulchanskyy, T. Y., et al. (2016). Tunable narrow band emissions from dye-sensitized core/shell/shell nanocrystals in the second near-infrared biological window. J. Am. Chem. Soc. 138, 16192-16195. doi: 10.1021/jacs.6b08973

Wang, G., Peng, Q., and Li, Y. (2011). Lanthanide-doped nanocrystals: synthesis, optical-magnetic properties, and applications. Acc. Chem. Res. 44, 322-332. doi: $10.1021 /$ ar $100129 p$

Wang, X., Valiev, R. R., Ohulchanskyy, T. Y., Agren, H., Yang, C., and Chen, G. (2017). Dye-sensitized lanthanide-doped upconversion nanoparticles. Chem. Soc. Rev. 46, 4150-4167. doi: 10.1039/C7CS00053G

Wang, Y., Wong, J. F., Teng, X., Lin, X. Z., and Yang, H. (2003). "Pulling" nanoparticles into water: phase transfer of oleic acid stabilized monodisperse nanoparticles into aqueous solutions of $\alpha$-cyclodextrin. Nano Lett. 3, 1555-1559. doi: $10.1021 / \mathrm{nl} 034731 \mathrm{j}$

Wei, W., Chen, G., Baev, A., He, G. S., Shao, W., Damasco, J., et al. (2016). Alleviating luminescence concentration quenching in upconversion nanoparticles through organic dye sensitization. J. Am. Chem. Soc. 138, 15130-15133. doi: 10.1021/jacs. 6b09474

Wu, S., Han, G., Milliron, D. J., Aloni, S., Altoe, V., Talapin, D. V., et al (2009). Non-blinking and photostable upconverted luminescence from single lanthanide-doped nanocrystals. Proc. Natl. Acad. Sci. 106, 10917-10921. doi: 10.1073/pnas.090 4792106

Yang, Y.-W., Sun, Y.-L., and Song, N. (2014). Switchable host-guest systems on surfaces. Acc. Chem. Res. 47, 1950-1960. doi: 10.1021/ar5 $00022 \mathrm{f}$

Zhou, H.-P., Xu, C.-H., Sun, W., and Yan, C.-H. (2009). Clean and flexible modification strategy for carboxyl/aldehyde-functionalized upconversion nanoparticles and their optical applications. Adv. Funct. Mater. 19, 3892-3900. doi: 10.1002/adfm.2009 01458

Zou, X., Xu, M., Yuan, W., Wang, Q., Shi, Y., Feng, W., et al. (2016). A water-dispersible dye-sensitized upconversion nanocomposite modified with phosphatidylcholine for lymphatic imaging. Chem. Commun. 52, 13389-13392. doi: 10.1039/C6CC07180E

Conflict of Interest Statement: The authors declare that the research was conducted in the absence of any commercial or financial relationships that could be construed as a potential conflict of interest.

Copyright (c) 2019 Wang and Chen. This is an open-access article distributed under the terms of the Creative Commons Attribution License (CC BY). The use, distribution or reproduction in other forums is permitted, provided the original author(s) and the copyright owner(s) are credited and that the original publication in this journal is cited, in accordance with accepted academic practice. No use, distribution or reproduction is permitted which does not comply with these terms. 